\title{
A UTILIZAÇÃO DE HISTÓRIAS NO MANEJO TERAPÊUTICO DE PACIENTES HOSPITALIZADOS*
}

\author{
THE USE OF STORIES IN THE THERAPEUTIC HANDLING \\ OF HOSPITALISED PATIENTS
}

Andréa Satrapa ${ }^{1}$

SATRAPA, A. A utilização de histórias no manejo terapêutico de pacientes hospitalizados. Rev. Bras. Cresc. Desenv. Hum., São Paulo, 12 (2), 2002.

Resumo: Este artigo proporciona elementos para uma reflexão sobre a utilização de histórias no acompanhamento clínico de pacientes somatizantes em internação hospitalar, visando tomar esse recurso instrumental. Para isso, serão utilizadas considerações teóricas articuladas à vinheta clínica. A intennação, geralmente breve, é um período de cnse, no qual as angústias persecutórias tendem a estar exacerbadas; decorre de uma situação de desequilíbrio psicossomático e é um período extremamente favorável ao aparecimento de comportamentos regressivos. As histórias têm como característica serem um fenómeno transicional; são estruturadas num registro mais próximo à fantasia, em grande sintonia com processos inconscientes; emergem de um contexto relacional como resultado de manifestações transferenciais e contratransferenciais; carregam um potencial metafor zante que permite a nomeação do indizível; enfim, por suas características transicional e lúdica e por seu potencial metaforizante, tal recurso se mostra um instrumento privilegiado para lidar com os aspectos mais primitivos implicados nas situações de regressão e de desequilíbrio psicossomático apresentadas pelos pacientes em questão.

Palavras-chave: histórias; manejo terapêutico, pacientes hospitalizados, psicossomático.

\section{INTRODUÇÃO}

A proposta desse trabalho é proporcionar elementos para reflexão sobre a utilização de histórias como um recurso terapêutico no acompanhamento clínico de pacientes hospitalizados, visando torná-lo instrumental. Histórias utilizadas em situações de cuidado e seus efeitos terapêuticas foram abordadas de diversas maneiras. Já em “As mil e uma noites” (GALLAND, s/d) Xerazade tem sua vida poupada e resgata a capacidade de amar de seu marido, o Rei Xariar, contando-lhe uma série de histórias ao longo de mil e uma noites.

As histórias também podem ser um valioso recurso nas consultas terapêuticas infantis, como mostrado por Gilberto SAFRA ( 1984) e no trabalho terapêutico com adultos (HISADA, 1998). Haveria, no entanto, alguma especificidade em sua utilização com pacientes que apresentam afecções somáticas em situação de internação hospitalar? Em minha prática clínica, comecei

\footnotetext{
* Trabalho apresentado no 111 Simpósio de Psicossomática Psicanalítica (Instituto Sedes Sapientiae, São Paulo, 2001). Em A Psicanálise no Século XXI: Um Momento de Reflexão (IPUSP, São Paulo, 2002) e no $1^{\circ}$ Congresso Brasileiro Psicologia: Ciência e Profissão (USP. São Paulo, 2002), tendo por base a Monografia para conclusão do Curso de Psicossomática do Instituto Sedes Sapientiae, São Paulo, 2001.

1 Membro do CDH. Rua Butantã, 136, apto. 92 - CEP: 01530-030 - São Paulo - SP. E-mail: asatrapa@uol.com.br
} 
a utilizar histórias de uma maneira bastante intuitiva. As histórias mostraram-se uma forma de intervenção bastante eficaz, especialmente com pacientes que encontravam-se hospitalizados. Esta observação, derivada da prática clínica, suscita algumas questões: por que este parece ser um recurso tão eficaz nesse contexto específico? Haveria algo que se passa nessa relação que contribuiria para isso? É sobre estas questões que me proponho a refletir.

\section{HISTÓRIA: UM RECURSO LÚDICO}

Gilberto SAFRA (1984) mostrou a possibilidade do uso de histórias como um importante meio de intervenção em uma abordagem psicoterapêutica breve, em um contexto de consultas terapêuticas com crianças. As histórias infantis foram escolhidas como instrumento privilegiado de comunicação, pois além de serem lúdicas, são transicionais ${ }^{2}$ e permitem à criança encontrar um sentido para suas experiências, dentro de uma estrutura de relações. Desse modo, para ser útil a história deve conter a angústia básica da criança, seus mecanismos de defesa, o tipo de relação objetal e um personagem que funcione como um objeto compreensivo que ajuda na integração da personalidade, bem como possíveis soluções do conflito. A história é elaborada junto com os pais e são criadas também outras versões do mesmo tema.

A permanência dos pacientes no hospital, durante a internação, é geralmente breve e requer um tipo bastante específico de atuação. As histórias podem ser de grande utilidade em intervenções breves, como mostrado por SAFRA (1984); mas essa conclusão poderia ser generalizada para o contexto de psicoterapia breve com adultos? Os objetivos dos trabalhos realizados por SAFRA (op. cit.) e no hospital são semelhantes: o manejo das angústias emergentes em um período crítico da vida; os métodos utilizados, no entanto, são dife- rentes: no hospital, o número de contatos com o paciente é incerto e a formulação da história não é o objetivo principal desses contatos. Ainda assim, as histórias parecem facilitar, também para os adultos, que um sentido para suas experiências seja encontrado.

Bruno BETTELHEIM (1980) aborda as semelhanças e diferenças entre as diversas formas de narrar uma história e suas implicações, que diferem para adultos e crianças.

Tanto os mitos, como os contos de fadas e as fábulas falam-nos em uma linguagem de símbolos, representando conteúdos inconscientes, que dirigem-se simultaneamente à nossa mente consciente e inconsciente, ao id, ego e superego ${ }^{3}$ e também às nossa necessidades de ideais de ego. Há, no entanto, diferenças fundamentais entre eles.

Os contos de fada, caracteristicamente, não fazem solicitações, mas reasseguram, dão esperanças de um futuro feliz através de um final sempre feliz, otimista. Lidando de modo indireto e sem solicitações com os conflitos inconscientes que aborda, descreve uma integração do ego que permite uma satisfação apropriada dos desejos do id, sendo por isso, especialmente adequados para as crianças.

Para os adultos, diferentemente das crianças, uma ampla gama de histórias pode funcionar como veículo de comunicação e de facilitação no encontro de sentido para experiências pungentes e mobilizadoras de angústia. Contos de fadas, mitos e fábulas podem ser utilizados, pois um adulto dispõe de recursos acumulados ao longo do caminho que percorreu em seu processo de desenvolvimento, que ainda não estão disponíveis à criança. Uma história que apresente o conflito, a angústia dele decorrente, a solução encontrada pelo sujeito e as conseqüências dessa solução parece ser suficiente para desencadear um movimento associativo e (re)estabelecer a comunicação entre o paciente e o seu mundo interno, como também com o terapeuta, sem necessariamente apresentar outras soluções que levem a um final feliz.

2 Este conceito será apresentado na página 6?.

3 Segundo LAPLANCHE \& PONTALIS (1997), id, ego e superego são as 3 instâncias da personalidade, como descritas por FREUD na $2^{\mathrm{a}}$ teoria teoria do aparelho psíquico. O id é o reservatário inicial da energia psíquica, constituindo-sc no polo pulsional da personalidade. Seus conteúdos são inconscientes, tanto hereditários e inatos como recalcados c adquiridos. Entra em conflito com o ego e o superego. que geneticamente são suas diferenciações. Os limites que separam o id das suas diferenciações não são bem definidos. O ego é a instância mediadora entre as exigências do mundo, as reivindicações do id e a severidade do superego. São atribuídas a ele as mais diversas funções, desde o controle da motilidade e da percepção, até a utilização de uma série de mecanismos de defesa. É mais vasto que o sistema Pré Consciente-Consciente. pois suas operações defensivas são em grande parte inconscientes. O superego exerce o papel de um censor em relação ao ego, sendo suas funções a consciência moral, a autoobservação e a formação de ideais. Em grande parte inconsciente, é classicamente definido como herdeiro do complexo de Édipo, constituindo-se a partir da interiorização das exigências e interdições parentais. Nem o ego nem o.superego são instâncias francamente autónomas em relação ao id. 
Mas, por que as histórias são terapêuticas? Qual ou quais de suas características estão implicadas na produção desse efeito?

\section{FENÔMENO TRANSICIONAL}

O conceito de espaço transicional, formulado por WINNICOTT (1975), pode nos mostrar um caminho. O espaço transicional constitui uma área intermediária de experimentação, para a qual contribuem as realidades externa e interna. Pertence à zona da ilusão, entre a fantasia e a realidade, na qual pode ser estabelecida uma relação com o objeto de modo pessoal e significativo. É nesse espaço que a realidade, através da capacidade criativa do indivíduo, poderá ser transformada em algo subjetivo, com significação própria. É nessa área que encontram-se o brincar, a arte, a religião e a imaginação.

Para SAFRA (1984), as histórias infantis são claros exemplos de fenômenos transicionais, pois no mundo do "faz de conta" a criança procura alívio para as tensões decorrentes do contato da realidade externa com a interna, como também elas auxiliam o desenvolvimento do ego e do sentido de realidade, facilitando a capacidade simbólica. Sueli HISADA (1998) acrescenta que, para os adultos, permitem que aspectos mais primitivos sejam revividos de forma não persecutória e, na relação terapêutica, permitem que o paciente encontre um sentido para suas experiências, podendo então integrar partes dissociadas de seu eu.

A própria maneira de intervir pode constituir-se (ou não) em um fenómeno transicional. A forma como a comunicação é estabelecida com o paciente é fundamental para que ele a introjete e assimile, principalmente quando há um incremento das ansiedades persecutórias. A comunicação estabelecida na forma de uma estória ofertada ao paciente guarda esse caráter de transicionalidade, pois o sentido não Ihe é imposto e ele é livre para interpretá-la como quiser e puder, conforme seus interesses e suas necessidades. Mas quanto aos adultos, haverá alguma situação na qual a utilização de histórias, entendidas como recursos transicionais, mostra-se particularmente eficaz?

HISADA (1998), que utilizou histórias no processo psicoterapêutico de adultos, relata que esse recurso mostrou-se de grande auxílio nos momentos de maior resistência, exercendo funções psíquicas como: conter angústias; facilitar a função de comunicação no processo terapêutico; reconhecer o material que pertence a seu percurso de vida.

Ela ressalta que "talvez a estória seja mais eficaz quando utilizada na fase de angústia mais intensa, quando o paciente está em maior contato com seu lado infantil, facilitando em seguida a expressão de suas vivências emocionais" (HISADA, 1998, p. 56).

\section{REGRESSÃO}

O período de internação hospitalar é, em geral, um período de crise, no qual as angústias persecutórias tendem a estar exacerbadas, especialmente se a internação é cirúrgica. Além disso, o ambiente hospitalar coloca o paciente em situação extremamente favorável ao aparecimento de comportamentos regressivos. O protótipo disso é a UTI, na qual ele permanece preso ao leito, completamente dependente dos cuidados de terceiros até mesmo para o exercício das mais básicas funções vitais.

GURFINKEL (1996) mostra que, na metapsicologia e na clínica psicanalítica, o estudo dos fenômenos regressivos ganhou outros contornos a partir de FERENCZI (apud GURFINKEL, op. cit.) e seus estudos sobre o desenvolvimento do eu; de BALINT (apud GURFINKEL, op. cit.) que aprofundou-se na teorização sobre os aspectos terapêuticos da regressão, e de WINNICOTT, para quem "regressão significa regressão à dependência e não especificamente regressão em termos de zonas erógenas" (1993, p. 427), abrindo novo campo de estudos sobre o tema a partir de suas concepções sobre o desenvolvimento emocional primitivo: a regressão a um estádio anterior do desenvolvimento quando, na presença de um ambiente favorável, pode haver a retomada do desenvolvimento. O conceito passou a trazer, desta forma, um inegável aspecto de esperança. WINNICOTT (1993) ressalta a importância do fornecimento de um setting adaptado adequadamente para dar continência às necessidades que surgem a partir da regressão. Mesmo uma interpretação pode ser vivida como invasão, posto que pressupõe certa organização mental que não está acessível nos momentos regressivos.

Ressaltada a importância clínica dos processos regressivos no âmbito hospitalar, fica mais evidente o potencial da utilização de histórias como recurso terapêutico nesse contexto. O próprio ato de contar histórias evoca infância e, conseqüentemente, função materna. A despeito de seu conteúdo, os aspectos sensoriais envolvidos no relato de história, como ritmo da fala e tom da voz, remetem às cantigas de ninar, também utilizadas para induzir o sono das erianças. As histórias são estruturadas num registro menos formal e rigoroso que outros instrumentos terapêuticos, mais próximo à fantasia, na fronteira do registro primário, em grande sintonia com processos inconscientes o que também as coloca mais próxi- 
mas portanto, dos eventos somáticos. Inicialmente, é através do exercício da função materna que o bebê pode passar de sujeito biológico a sujeito psicológico; e através da relação com outro ser humano, que nomeia as aflições do bebê, outorgando-lhes um significado, que as manifestações inicialmente vividas e expressas pelo soma podem ser representadas e ascender a manifestações psíquicas. O contato terapêutico que propicia que uma história possa ser oferecida a um paciente guarda esse caráter maternante pois, ao deixar-se afetar pelas aflições do paciente, o terapeuta tem condições de significar o que foi apreendido contratransferencialmente ${ }^{4}$.

A utilização da estória não é previamente programada quanto ao momento de sua apresentação, nem quanto à sua forma e conteúdo. A história surge do contexto relaeional que se dá em um momento especifico, caracterizando um processo que não é totalmente consciente, visto que o próprio terapeuta opera próximo do registro regredido do paciente. Em geral, uma história ou episódios dela surgem na mente do terapeuta como uma resposta às angústias que nele foram mobilizadas contratransferencialmente; situações de resistência mais intensa e de interrupção da comunicação devido ao incremento da angústia são especialmente sensíveis a essa forma de intervenção. Desse modo, mesmo uma história conhecida sofre alterações e recortes que, posteriormente, verifica-se ser o resultado de manifestações transferenciais e contratransferenciais. Todas essas características infantis parecem ser, de fato, as que fazem deste recurso um instrumento privilegiado para lidar com os aspectos mais primitivos implicados nas situações de regressão e de desequilíbrio psicossomático.

\section{POTENCIAL METAFORIZANTE}

Já vimos que as histórias são recursos transicionais e que apresentam características infantis, o que as torna um instrumento de grande utilidade no manejo das situações de regressão e de desequilíbrio psicossomático. No entanto, elas apresentam ainda outra qualidade, que nos ajudará a ampliar a compreensão sobre a eficácia de sua utilização em tais circunstâncias. As histórias, assim como os poemas e as canções, são próximas da metáfora e, por isso, carregam um potencial metaforizante, podem tornar-se palavras que pescam não-palavras, parafraseando o sensível título do livro de Helena Kon ROSENFELD (1998). Ao abordar a afinidade estrutural entre a interpretação psicanalitica e a metáfora, ela diz:

"O trabalho que a interpretação psicanalítica faz poderia ser pensado em termos de tentativa de inscrição - e nesse caso as idéias do "fundar", do "dar existência " e do "dar à luz" que a metáfora inspira - ou em termos de articulação, ligação, costura bem arrematada entre registros diferentes. entre afeto e representação, entre experiências indizíveis e palavras pronunciadas. Não é um trabalho.simples, e já vimos que não se trata, por exemplo, de pôr os afetos em palavras. Trcrta-se, sim de dar um nome que, ao invés de falar à distância do afeto, ao invés de designá-lo "desafetadamente", petrificadamente, possa falar dele de perto, de tão perto que o afeto fique dentro do nome, encarnado nele. Essa é a "fala afetada", fala enraizada no afeto, que pode articular os registros sem perdê-los, ou que pode criar um registro ainda inédito"

(ROSENFELD, I998, pp. 143-144).

O desequilíbrio psicossomático remete-nos aos afetos que estão aquém das representações, seja por uma impossibilidade circunstancial de articulá-los psiquicamente ou por uma impossibilidade estrutural de fazê-lo. Os recursos psíquicos que permitem o manejo dos afetos podem não estar disponúveis naquela circunstância ou podem nunca ter estado: em ambas as situações, no entanto, há um transbordamento para o soma do que não pôde ser psiquicamente capturado, ligado, articulado. $^{5}$

A metáfora, e também a história por seu potencial metaforizante, quando justas, oportunas, favorecem essa captura, permitindo que uma experiência afetiva indizível ganhe contornos, receba uma ou mais signirficações e se conecte com outras representações e mesmo com experiências do mundo externo: a possibilidade de circulação de afeto brota em um sujeito afetado por uma metaforização, o que favorece o restabelecimento do equilíbrio psicossomático.

Restaria, ainda, uma última questão a ser abordada: há diferenças marcantes entre a histó-

4 Segurado LAPLANCHE E PONTALIS (1997), transferência “designa cm psicanálise o processo pelo qual os desejos inconscientes se atualizam sobre determinados objetos, no quadro de um certo tipo de relação estabelecida com eles e, eminentemente, no quadro da relação analítica. Trata-se aqui de uma repetição de protótipos infantis vivida com um sentimento de atualidade acentuada. É à transferência no tratamento que os psicanalistas chamam a maior parte das vezes transferência, sem qualquer outro qualificativo “(LAPLANCHE \& PONTALIS, 1997, p. 514) é contratransferência refere-se ao "conjunto das reaçõcs inconscientes do analista à pessoa do analisando e, mais particularmentc, à transferência deste” (p. 102) 
ria infantil e a interpretação psicanalítica? Se existem, o que demarca tais diferenças? O potencial metaforizante de ambas parece indicar uma semelhança estrutural entre elas, como a apontada por ROSENFELD (1998) entre a metáfora e a interpretação. No entanto, por ser um recurso transicional, a forma de apresentação e a liberdade de uso da história pelo paciente parecem destacá-la da interpretação. Sem poder apresentar uma resposta mais conclusiva a esta indagação, fica a sugestão para futuras investigações.

\section{VINHETA CLÍNICA}

\section{Sr. Caçador}

Sr. Caçador era um paciente a quem tudo já havia acontecido. Viera transferido de um outro hospital, no qual ficara internado por mais de um mes devido a um acidente vascular cerebral (AVC) seguido de meningite. Foi então diagnosticada uma endocardite bacteriana, que precisou ser tratada cirurgicamente. A recuperação foi lenta e difícil e também ocorreram complicações, o que exigiu um tempo prolongado de internação e alguns retornos à Unidade Terapêutica intensiva (UTI).

Entre as scqüelas do AVC, a dificuldade para falar tornava a fala um pouco difícil. Comigo, ele pouco falava, limitando-se a abordar a situação atual, seu estado de saúde, suas limitações físicas. Às vezes, chorava por todo o tempo.

Da última vez em que retornou à UTI devido a uma infecção rara, o Sr. Caçador abateu-se bastante. Permaneceu em isolamento devido à natureza contagiosa da infecção e teve que ser entubado por duas vezes, durante as quais permaneceu inconsciente. Após a segunda extubação, já há 14 dias na UTI, mostrava-se prostrado, desanimado, desinteressado pela vida. Apontei-lhe que percebia que ele estava cansado, entregue, e ele concordou com uma facilidade que me surpreendeu, dizendo que havia desistido de viver, havia se cansado de tudo aquilo pois sabia que não havia mais nada a se fazer. Após tentar aproximar-me dele e de seu estado psíquico através de apontamentos e formulações mais convencionais, sem sucesso, lembrei-me de uma história. Perguntei-lhe se gostaria de ouvir e, como concordasse, comecei a contar-lhe:

Era uma vez uma tribo, na África, que vivia da caça e da coleta de alimentos. Um dia, todos os homens da tribo saíram para caçar. Um dos africanos distraiu-se e, quando deu por si, já havia anoitecido, ele estava sozinho e perdido!
Começou a procurar um bom lugar para passar a noite, mas escutou um ruido familiar e assustador. Um leão estava por perto e certamente percebera o desamparo de sua presa, procurando encurralá-la. Assustado, o africano passou a fugir, mas quando pensava ter conseguido despistar o leão, de novo ouvia seus ruídos... ele parecia estar em todos os lugares!

No entanto, seus companheiros continuavam na floresta a procurá-lo. Só que, em sua crescente aflição, não mais conseguia distinguir os sons do leão dos outros sons. A tensão e o medo transformaram-se em pavor. O dia não tardaria a clarear, mas nem isso ele foi capaz de perceber! Então, ao ouvir um rugido, ao invés de fugir, precipitou-se direto para a boca do leão. Seus companheiros escutaram o horrível barulho, pois estavam muito perto, mas nada mais puderam fazer...

A reação do Sr. Caçador à essa história foi imediata. Seus comentários limitaram-se a exclamações do tipo: “Nossa, os amigos...”, “Estavam tão perto!”, “Ele não estava sozinho!”. O leito onde estava isolado era próximo à sala da enfermagem, de modo que sempre havia gente passando em frente à sua porta. Começou a chamar, com a mão, as pessoas que passavam por ali. A partir dai, dificilmente ficava sozinho. Sua melhora física foi sensível. Em 5 dias, recebeu alta da UTI. Após mais 12 dias no quarto, recebeu alta hospitalar. Mesmo no quarto, em todos os atendimentos efetuados desde então, ele comentava sobre a história, dizendo que havia sido muito importante para ele.

Apenas depois dei-me conta das modificações que havia feito: eu acrescentara os companheiros de caçada e seus ruídos misturados aos do leão. E só então percebi que, de fato, havia introduzido a mim e à equipe de saúde, assustando-o com o "barulho" que fazíamos ao tentar ajudá-lo! Ao abordar suas intensas angústias e seus conflitos de forma lúdica e indireta, a história permitiu que a comunicação fosse restabelecida entre nós e que ele pudesse utilizar seus recursos disponíveis, internos e externos, para viabilizar a recuperação.

\section{CONCLUSÃO}

Tentando compreender a eficácia da utilização de histórias no acompanhamento psicoterapêutico de pacientes adultos somatizantes durante a internação hospitalar, com o intúito de tornar essa técnica instrumental, foram utilizados alguns conceitos como eixo para dar

5 Tais idéias baseiam-se nas concepções de Pierre MARTY. Para um aprofundamento no assunto, remeto o leitor a MARTY (1993). 
suporte ao seu uso: fenômeno transicional, regressão e potencial metaforizante.

De um modo geral, a permanência dos pacientes em internação é breve e este, com freqüência, é um período de crise, no qual as angústias persecutórias tendem a estar exacerbadas, constituindo-se também, pelas características dos cuidados prestados aos pacientes, numa situação extremamente favorável ao aparecimento de uma dinâmica regressiva. Tanto a regressão como a situação de desequilíbrio psicossomático que culminou no adoecimento causador da internação hospitalar implicam na necessidade do manejo dos aspectos primitivos nelas implicados.

Histórias que apresentem a angústia básica do sujeito, a solução encontrada para lidar com ela e as conseqüências dessa solução, de forma lúdica, são um bom recurso quando usadas em intervenções terapêuticas breves. Guardam a característica de um fenômeno transicional, como definido por Winnicott, pois seu sentido não é imposto ao paciente, que é livre para interpretá-la como quiser e puder e, por essa característica, mostram-se especialmente eficazes quando apresentadas em situações de resistência mais intensa e de interrupção da comunicação devido ao incremento da angús- tia. Por serem estruturadas num registro mais próximo à fantasia, na fronteira do registro primário, em grande sintonia com processos inconscientes, guardam proximidade com os aspectos primitivos implicados nos eventos regressivos e somáticos. Emergem, sem programação prévia, de um contexto relacional com características maternantes, como resultado de manifestações transferenciais e contratransferenciais. Oferecem um potencial metaforizante que permite a captura de vivências afetivas indizíveis, que podem então ser significadas e conectadas a outras representações, possibilitando a circulação do afeto e favorecendo o equilíbrio psicossomático. Devido ao estado regredido em que se encontra o paciente, as características transicional e lúdica e o potencial metaforizante das histórias são, a meu ver, os principais operadores do poder e da eficácia desse instrumento.

\section{AGRADECIMENTOS}

Agradeço a Sidnei José Caseto, professor do Curso de Psicossomática do instituto Sedes Sapientae, pelo incentivo e pela interlocução atenta.

\begin{abstract}
This article provides elements for a reflection on the use of stories in the clinical monitoring of hospitalised somatizing patients, aiming to make this resource become instrumental. To achieve this, theoretical considerations articulated with the clinical vignette are used. The hospitalisation period is generally a short period of crisis, in which the persecution anxiety tends to be exacerbated; it derives from a situation of psychosomatic unbalance and it is a period that is extremely favourable to the emergence of regressive behaviours. Stories are a transitional phenomenon; they are structured in a register that is close to fantasy, and have a strong relationship with unconscious processes; they emerge from a relational context as the result of transferential and counter-transferential manifestations; they carry a metaphoric potential that allows the assigning of a name to the unspeakable. In short, due to their transitional and playing characteristics and to their metaphoric potential, this resource is a powerful instrument to deal with the most primitive aspects involved in the situations of regression and psychosomatic unbalance presented by the patients in question.
\end{abstract}

Key words: stories; therapeutic handling; hospitalised patients; psychosomatic. 


\section{REFERÊNCIAS BIBLIOGRÁFICAS}

BETTELHEIM, B. A psicanálise dos contos de fadas. Rio de Janeiro: Paz e Terra, 1980.

GALLAND, A. (versão de). As mil e uma noites. Rio de Janeiro: Livraria Paisagem Rio, s/d.

GURFINKEL, D. Psicanálise, regressão e psicossomática: nas bordas do sonhar. Revista Percurso, São Paulo, 16: 69-80, 1996.

HISADA, S. A utilização de histórias no processo psicoterápico: uma proposta Winnicottiana. Rio de Janeiro: Revinter, 1998.

LA PLANCHE, J.; PONTA LIS, J. B. Vocabulário da psicanalise. São Paulo: Martins Fontes, 1997.

MARTY, R Clínica e teoria. In: MARTY, R. A psicossomática do adulto. Porto Alegre: Artes Médicas, 1993. p. 12-46.
ROSENFELD, H. K. Palavra pescando não-palavra: a metáfora na interpretação psicanalítica. São Paulo: Casa do Psicólogo, 1998.

SAFRA, G. Um método de consulta terapêutica através de estórias infantis. São Paulo, 1984. [Dissertação de Mestrado - Psicologia Clínica do instituto de Psicologia da Universidade de São Paulo].

WINNICOTT, D. W. O brincar e a realidade. Rio de Janeiro: Imago, 1975.

WINNICOTT, D. W. Retreimento e regressão. In: WINNICOTT, D. W. Textos selecionados: da pediatria à psicanálise. Rio de Janeiro: Francisco Alves, 1993. p. 427-433.

Recebido em 27/06/2002

Modificado em 21/08/2002

Aprovado em 25/08/2002 